\title{
Erratum to: Differential contribution of aortic and carotid sinus baroreflexes to control of heart rate and renal sympathetic nerve activity
}

\author{
Kei Ishii $^{1} \cdot$ Mitsuhiro Idesako $^{1} \cdot$ Kanji Matsukawa $^{1}$
}

Published online: 8 August 2015

(C) The Physiological Society of Japan and Springer Japan 2015

\section{Erratum to: J Physiol Sci}

DOI 10.1007/s12576-015-0387-2

In the original publication of the article, the given name and family name of the second author were interchanged. The correct name should appear as "Mitsuhiro Idesako". The author name should also be corrected in the "Author contribution' section as follows:

\section{Author contribution}

K.M. designed the experiments; K.I., M.I., and K.M. performed the experiments; K.I. and M.I. analyzed the data; K.I. and K.M. drafted the article; K.M. revised the article critically for intellectual content. All authors approved the final version of the manuscript.

The online version of the original article can be found under doi:10.1007/s12576-015-0387-2.

Kanji Matsukawa

matsuk@hiroshima-u.ac.jp

1 Department of Integrative Physiology, Graduate School of Biomedical and Health Sciences, Hiroshima University, 1-2-3 Kasumi, Minami-ku, Hiroshima 734-8551, Japan 